\title{
O ENCONTRO TRANSFORMADOR EM MORADORES DE RUA NA CIDADE DE SÃO PAULO
}

\author{
Aparecida Magali de Souza Alvarez \\ Faculdade de Saúde Pública da Universidade de São Paulo \\ Augusta Thereza de Alvarenga \\ Faculdade de Saúde Pública da Universidade de São Paulo \\ Nelson Fiedler-Ferrara \\ Instituto de Física da Universidade de São Paulo
}

RESUMO: Este trabalho busca a caracterização do encontro transformador entre seis moradores de rua e duas professoras na cidade de São Paulo. Este encontro possibilitaria a transformação psíquica dos envolvidos, no sentido de promover o despertar das potencialidades de self, do sentido de suas vidas, contribuindo para a promoção da resiliência. À resiliência, compreendida como "a capacidade humana de fazer frente às adversidades da vida, superá-las e sair delas fortalecido ou inclusive transformado", foi associada a noção do ágape, amor ao próximo, articulado com conceitos de self e falso self. Neste estudo longitudinal, o morar na rua surgiu como situação existencial excludente, favorecendo envolvimentos com droga e criminalidade. Revelou-se nova configuração nas psiques dos moradores de rua - em movimento transformador - junto às pessoas que foram seus pontos de apoio positivos. No entanto, tiveram dificuldades na permanência nesse processo sem o apoio mais amplo da Sociedade Civil e Estado.

PALAVRAS-CHAVE: Encontro Transformador - Resiliência - Moradores de rua - Saúde Pública - Exclusão social.

\section{THE TRANSFORMING ENCOUNTER IN HOMELESS PEOPLE IN SÃO PAULO CITY}

ABSTRACT: This work aims to characterize the transforming encounter between six homeless people and two teachers in the city of São Paulo. This encounter would enable the psychic transformation of the people involved, promoting the awakening of the potentialities of the self, of the meaning of their lives, and contributing to the promotion of resilience. Resilience is understood as "the human capacity to cope with life's adversities, to overcome them and to become stronger or even be transformed because of them". This was associated with the notion of agape, love for one's fellow humans, articulated with the concepts of self and false self. In this longitudinal study, dwelling in the street emerged as an excluding existential situation, favoring involvements with drugs and criminality. A new configuration in the psyches of the homeless was revealed - in a transforming movement -, in contact with people who were their positive supporting points. However, they had difficulties to remain in this process without the broader support of the Civil Society and of the State.

KEY- WORDS: Transforming Encounter - Resilience - Homeless People - Public Health - Social exclusion.

\section{INTRODUÇÃO}

Este trabalho é parte de pesquisa cujo problema de investigação se constituiu na busca da caracterização de uma interação psicossocial específica entre os seres humanos, denominada de encontro transformador, que possibilitaria a transformação psíquica dos envolvidos, no sentido de promover o despertar das potencialidades de self, com a retomada do sentido de suas vidas, contribuindo para a promoção da resiliência. Ao conceito de resiliência, compreendido como a "capacidade humana de fazer frente às adversidades da vida, superá-las e sair delas fortalecido ou inclusive trans- formado" (GROTBERG, 1996), e aprofundado por Alvarez $(1999,2003)$, foi associada a noção de ágape definido como "amor às outras pessoas humanas, amor ao próximo" (BOLTANSKI, 1990). Essa noção - articulada com outros conceitos - será melhor explicitada em suas características em outras seções deste artigo, sem a pretensão de esgotarmos sua complexidade. Aos conceitos referidos acima foram articulados os conceitos de self e falso self.

A respeito do self e falso self Gilberto Safra explicita que Winnicott traz a idéia de um self central como potencial herdado pela criança que, já 
desde o início de sua vida, através de sua interação com o ambiente, com o favorecimento deste estaria experimentando um senso de continuidade de ser e adquirindo gradualmente, à sua maneira e em seu próprio ritmo, uma realidade psíquica e um corpo próprios. Completa o autor que esse período caracteriza-se pelo estabelecimento do self e do mundo subjetivo (SAFRA, 1999). Safra relata ainda que um indivíduo, quando vivenciando situações de adversidade, poderia "desenvolver um movimento onde reteria alguma coisa de pessoal, mesmo um segredo, nem que seja o respirar". Desenvolveria um falso self que é um "aspecto do self que protege e oculta o self verdadeiro como reação às falhas de adaptação. $O$ falso self organiza-se como um padrão de conduta que corresponde à falha ambiental" (SAFRA, 1995:47).

Winnicott (1975) teorizou ainda a respeito de um conceito que estaremos introduzindo neste trabalho, ou seja, a respeito de uma área de desenvolvimento e experiências do ser humano que denominou terceira área ou espaço potencial.. Essa terceira parte da vida psíquica do ser humano seria uma área intermediária de experimentação para a qual contribuem tanto a realidade interna do indivíduo quanto a vida externa, ou seja, o ambiente, o outro que o constitui. Ao abordar a díade mãe-bebê, essa mãe é referida em muitos momentos de sua obra como o ambiente. Referindo-se, portanto, inicialmente ao bebê e sua mãe ao falar da terceira área, estendeu-a depois ao ser humano adulto e à utilização que esse adulto faz desse espaço potencial, denominando-o também como área do brincar.. Ao abordar essa área, de importância central em seu pensamento, Winnicott afirma que a psicoterapia se efetua na sobreposição de duas áreas do brincar, ou seja, a do paciente e a do terapeuta, sendo que a psicoterapia trata de duas pessoas que brincam juntas. Conclui que, onde o "brincar não é possível, o trabalho efetuado pelo terapeuta é dirigido no sentido de trazer o paciente para um estado em que não é capaz de brincar para um estado em que o é" (WINNICOTT, 1975:59). Reafirma, ainda, esse autor, que "o brincar implica confiança e que este pertence ao espaço potencial..." (WINNICOTT, 1975:76).

Objetivava-se, neste trabalho, identificar as características psicossociais constitutivas do processo de encontro transformador entre moradores de rua envolvidos (ou não) com a criminalidade e segmentos da sociedade civil considerados como seus pontos fixos/pontos de apoio, que possibilitassem melhor compreensão do desenvolvimento da capacidade de resiliência do ser humano. O ponto-fixo/ponto de apoio, segundo Sueli
Damergian (1988) e aprofundado por Alvarez (1999, 2002, 2003), surge como um objeto bom que deve ser oferecido ao ser humano pelo meio (no caso do bebê, pela mãe ou substituta). Sem isto, o núcleo do ego não se estrutura, a personalidade não se desenvolve, a identidade não se constrói. Podem ser os 'portos seguros' introjetados que auxiliam na nova configuração do rumo, do sentido da vida.

Como Ultimate Objectif visava-se a contribuir para o (re)equacionamento das ações que buscam atender às populações de rua e a (re)definição de políticas públicas, tendo em vista o amplo significado social que esta parcela da população assume no contexto de metrópoles brasileiras, notadamente a paulistana. Em estudo longitudinal, ao longo de cinco anos, de 1998 a 2002, através de Histórias de Vida, foram realizadas entrevistas abertas e semi-estruturadas, fotografias, registros em Diário de Campo, coletas de desenhos e artesanatos realizados pelos sujeitos de observação: seis moradores de rua, alguns ligados ao crime e consumo de drogas, e duas professoras aposentadas - não moradoras de rua - que estabeleceram relações de ajuda a eles. Na interpretação dos dados contemplou-se o emprego de conceitos pertinentes a determinadas teorias da Psicologia, Geografia, Antropologia, Sociologia, às abordagens da Complexidade de Edgar Morin e da Sistêmica, na busca do diálogo entre diferentes disciplinas.

\section{SITUAÇÃO EXISTENCIAL EXTREMA}

Conhecemos os moradores de rua, sujeitos de observação deste trabalho, em 1998, quando estes estavam instalados em pequena praçamaloca localizada no bairro da Bela Vista, no centro da cidade de São Paulo. Essa pequena praça localizava-se em região marcada pela presença de bares, restaurantes, teatros e poderíamos defini-la como uma mancha de lazer, conforme o uso que Magnani faz desse conceito, ao explanar sobre padrões de uso e ordenação do espaço urbano. Para este autor, as "manchas são áreas contíguas do espaço urbano dotadas de equipamentos que marcam seus limites e viabilizam - cada qual com sua especificidade, competindo ou complementando uma prática ou atividade predominante." (MAGNANI, 2002:22)

Identificamos aquele grupo de seres humanos adultos vivendo situações existenciais extremas. O nome maloca - atribuído pelos moradores de rua de São Paulo a um modo específico de viver em grupos na rua, sem proteção aos próprios corpos, embriaguez, mendicância, exposição a violências - indicava o modo de vida que ali se desenvolvia, considerado por eles mesmos como pri- 
são difícil de sair. As relações desenvolvidas entre os componentes do grupo, o uso de drogas, o estado de abandono, de exclusão, os empurravam para baixo e cada vez mais para as sarjetas, sendo que para alguns o trânsito pela droga - notadamente o crack - e a criminalidade tornou-se quase inexorável. O sentimento da vergonha foi manifestado por eles, face à situação em que viviam.

Ao discorrer a respeito dos sentimentos, Erikson relata que os adultos -inclusive os aparentemente maduros e não neuróticos - mostram-se muito sensíveis à possibilidade de uma vergonhoso descrédito. Ao abordar a manifestação desse sentimento esse autor coloca que "a vergonha se manifesta logo por um impulso de esconder o rosto ou de, no mesmo instante e lugar, afundar no chão" (ERIKSON, 1976:232).

Os moradores de rua observados revelaram, inclusive, o sentimento de desconfiança na sociedade, nos provedores externos e na própria capacidade para enfrentar suas necessidades e desejos mais urgentes. Prosseguindo na análise a respeito dos sentimentos manifestados pelos sujeitos de observação deste trabalho, refletimos sobre a advertência de Erikson sobre a concepção errônea de que o sentimento positivo de confiança seria uma conquista, definitivamente alcançada em determinado estado. Tal autor afirma que os sentimentos negativos (como a desconfiança básica, por exemplo) são e continuam a ser durante toda a vida a antítese dinâmica dos positivos, apontando que a "personalidade trava combate continuamente com os perigos da existência, mesmo quando o metabolismo do corpo luta com a deterioração" (ERIKSON, 1976:251). Ele explicita, ainda, que o restabelecimento de um estado de confiança seria o requisito básico para a terapia.

Entendemos, face à essa colocação, que seria possível ser restabelecido/estabelecido - no ser humano adulto com os quais trabalhávamos na pesquisa - um sentimento de confiança de que tenha sido frustrado na sua relação com a mãe/ cuidador, ou que tenha sido perdido como, por exemplo, quando na situação de morador de rua.

Assim, alguns dos sujeitos de observação, recordando a própria infância, denunciaram a ausência de mãe ou pai devotados que pudessem ampará-los em sua trajetória infantil. Soviético, um dos moradores da maloca, crescendo sem os pais pois estes haviam cometido crimes e estavam cumprindo penas em Penitenciárias - e entregue à própria sorte, iniciou-se cedo na vivência das transgressões, em busca da própria sobrevivência. Com várias passagens pela FEBEM (Fundação Estadual do Bem Estar do Menor), ao tornar-se adulto foi para a prisão, cumprindo 20 anos no Carandiru. Ao sair do presídio, analfabeto, começou a morar nas ruas, instalando-se na pequena praça-maloca, onde o conhecemos em 1998. Nessa mesma maloca e ano conhecemos Athos que nos revelou detalhes do ambiente em que vivera na infância, inadequado para uma criança. Revelou-nos, ainda, os crimes que cometera, quando em brigas matou dois moradores de rua.

Priscila, instalada em uma 'caverna' perto da maloca, buraco cavado próximo à Avenida 23 de Maio, denuncia situações de abandono e violência na infância. Identificamos nessa moradora de rua a ausência do ponto de apoio, da devoção de uma mãe suficientemente boa.. Segundo Winnicott, a mãe suficientemente boa - e neste caso não precisaria ser necessariamente a própria mãe do bebê - é "aquela que efetua uma adaptação ativa às necessidades de bebê, adaptação que diminuiria gradativamente e cujo êxito desses cuidados para com a criança depende da sua devoção e não do jeito ou esclarecimento intelectual" (WINNICOTT, 1975:25). A respeito da devoção, Gilberto Safra afirma que "ao falar-se de mãe devotada, está se falando de uma mãe que não perde de vista o ser de seu filho", contrapondo-se à "mãe aflita que, apesar de possuir uma ligação bastante intensa com o seu bebê, acaba por coisificá-lo, na tentativa de aplacar sua própria ansiedade e aflição" (SAFRA, 1999:75). Essa devoção, segundo Winnicott, tem a ver com a maternagem ou maternagem suficientemente boa, que são aqueles cuidados iniciais oferecidos pela mãe ou, ainda, pelo pai e demais familiares, essenciais à formação do indivíduo (WINNICOTT, 1988).

A moradora da 'casa caverna', maltratada pelo pai bêbado e sem conhecer a mãe, aponta o momento em que inicia sua vida de criança de rua: "Aí eu fiz uma mochilinha e saí de casa pro mundo..." Seu companheiro Paraíba, em liberdade condicional, desempregado e eventualmente guardando carros, e vivendo com ela na casa caverna, desespera-se com a lembrança da mãe morta, odiando e acusando o pai de ser o causador das desditas da mãe. Em uma briga pelo ponto de guardar carro, mata outro morador de rua e volta para a prisão.

\section{A CIDADE CINDIDA E AS PONTES HUMANAS: PROVIDÊNCIAS DE TRÂNSITO RELACIONAL}

A cidade de São Paulo foi considerada em nossa pesquisa como portadora das características de cidade de muros citada por Caldeira (2000:320), que denuncia, no concreto, a imensa fratura relacional que se alarga e se aprofunda entre as 
duas sociedades que vão emergindo no social brasileiro: de um lado, o segmento social dos integrados, com melhores, mais justas e corretas relações sociais (VÉRAS, 2001:38), relações essas cuja vivência pode ser nomeada por cidadania, e do outro o segmento social dos excluídos, com direito à exclusão integrativa, vil inserção marginal às sobras do banquete dos eleitos da cidade cindida. Soviético revela em sua fala e desenho, denominado por ele "Condomínio de luxo", a cisão entre essas duas sociedades e as conseqüências desse processo em pessoas que, como ele, integram o lado dos excluídos:

"Sábado, eu e uns moleques, a gente passava por um condomínio de luxo num bairro de São Paulo e ficamos parados, olhando e admirando, vendo uma coisa que a gente nunca viveu. Fomos então abordados pela polícia, mandando a gente cair fora. Em vez de oferecerem um prato de comida ou conversar um pouco, mandam cair fora... Não queremos esmola, queremos é um pouco de compreensão. Apesar de tudo isso que as pessoas tem: apartamento de luxo, piscina, perua pra levar os filhos na escola, a gente sabe que eles lutaram, mas tiveram um apoio melhor que é justamente o que falta para nós. Se o Brasil não tiver consciência, vai chegar o tempo que aquele que for honesto e trabalhador não poderá andar na rua. Então esta é a hipocrisia. São pessoas que têm condição de ajudar o próximo mas não se interessam. Eu não pintei esse desenho porque é a realidade da vida. É tudo negro. Na rua, por exemplo, as pessoas andam assustadas. Todos têm medo e até atravessam a rua de medo de ser assaltadas. Ninguém confia em ninguém. Se a gente olhar um pouco mais para alguém, a pessoa fica assustada, pensando que vai ser assaltada." (Soviético, morador de rua)

Muitos dos moradores de rua, os caídos (VIEIRA ET AL., 1994) pertencentes a esse segmento social de excluídos, perderam-se de si mesmos. Junto às perdas de endereços, certidões de nascimento, carteiras de identidades - símbolos de cidadania - entrecruzam-se as perdas de esperança, do sentido da vida, da vontade de viver. Enquanto alguns se afogam na bebida alcoólica ou nas drogas, amortecedoras da dolorosa agonia da falência psicossocial, outros, reagindo violentos, lançam-se ao crime, inserindo-se através dessa forma escusa nos processos sociais. Só então, ironicamente, tornam-se visíveis... e porque incomodam, porque agridem, porque ousaram sair das cavernas, ou porque ousam abrir os olhos e cobiçar os 'valiosos bens de consumo' que ornamentam a cidade atrás dos muros. É quando, paradoxalmente, ad- quirem um status - o de bandido! - aquele que dever ser banido, segregado aos espaços amontoados das prisões. Ironicamente, nessa hora, recobram o endereço e a identidade do prontuário policial...

A sociedade está doente, cindida, e não há perspectiva de cura próxima. Os meios de comunicação brasileiros exibem a todo momento ao vivo e em cores, em tempo real - a dinâmica doentia desse corpo social esfacelado. Esses retratos dinâmicos são oferecidos nos jornais nacionais televisivos como parte dos jantares de cidadãos que olham tudo atônitos e respiram aliviados quando o foco da emissora passa para cenas mais amenas. Teresa Cristina Carreteiro (1999), abordando a questão das drogas, violência e segmentos sociais precários do Rio de Janeiro, aponta para os mecanismos de defesa psíquicos ativados para fazer face às angústias constantes. São mecanismos que, segundo ela, permitem a justificação e racionalização das condutas daqueles que estão sob pressão dessas angústias. Afirma a autora que os mecanismos acionados são principalmente os de negação, isto é, "a distorção da realidade quando ela se apresenta muito violenta com pessoas que não fazem parte do círculo parental ou de amigos; a clivagem das representações: "A violência acontecerá contra os outros, não comigo!". Como se a força desses pensamentos pudesse criar uma camada protetora em torno das famílias e dos grupos. Observase também a repressão das emoções, a eufemização da violência (quando nomeiam uma pessoa assassinada como presunto, por exemplo, amenizando e banalizando o ato de sua morte, que assim tanto faz que tenha acontecido pela mão da polícia ou das facções criminosas ligadas ao tráfico de drogas). Esses mecanismos de defesa são individuais mas igualmente coletivos, pois permitem às pessoas na mesma situação ativarem reações semelhantes que coloquem à distância as fontes da ansiedade" (CARRETEIRO, 1999:121-130).

No entanto, se muitos da sociedade intramuros referida por Caldeira (2000:320) encontramse adormecidos para os problemas psicossociais que se avolumam ou permanecem paralisados pelo medo, há segmentos da sociedade que conseguem marcar presença junto aos que perderam o sentido da vida. Neste trabalho falamos de alguns destes que se erigiram como pontos-fixos/pontos de apoio, pontes humanas que - transpassando abismos relacionais - levam ao que nomeamos como encontro transformador. É quando presenciamos a professora Sílvia intermediando a correspondência entre a moradora da casa caverna, que estava hospitalizada pela tuberculose avançada e o seu com- 
panheiro Paraíba, que ficara vivendo na 'toca' de ambos. É quando, também, acompanhamos o depoimento de Lucinha que - muito além do simples ofício de professora - devotada e desafiadora, oferecia o endereço de sua residência para que o morador de rua - candidato a um trabalho - apresentasse à 'empresa' como sendo dele.

\section{A TRANSFORMAÇÃO:}

\section{CONFIGURANDO NOVA FORMA}

"Progredir, no caso da constituição da vida psíquica mas também em qualquer outro caso, implica organizar-se, conquistar formas e transformar-se" (LUÍS CLÁUDIO FIGUEIREDO, 2001) ${ }^{1}$.

Convidados por Sílvia e Lucinha, para comparecerem à escola onde elas alfabetizavam as populações de rua, no centro da cidade de São Paulo, alguns dos moradores de rua viveram processos de encontros transformadores com essas professoras.

Foi considerada, no início desse processo, a presença de certa unidade psíquica, por exemplo, em Soviético e Athos, que lhes permitira a sobrevivência nas prisões e nas ruas: um falso self bastante bem sucedido.

No entanto, apesar do sucesso dessa configuração psíquica dos moradores de rua - do falso self - não se extinguira neles a insatisfação e a procura de si-mesmos. Era necessário o restabelecimento do sentimento positivo de confiança para que pudessem olhar-se, permitindo assim que o self pudesse retomar seu acontecer dentro do processo maturacional com a facilitação de um meio ambiente humano (SAFRA, 1999). Suas potencialidades estavam à espera do outro significativo ou próximo devotado (WINNICOTT, 1975) que pudesse acompanhá-los no processo de autorealização.

Aborda ainda Safra a experiência do fenômeno do poético que seria aquele que articula, em um único fenômeno, a capacidade criativa dos seres humanos que se encontram, dando origem à comunicação humana, ao existir (SAFRA, 1999:20). Segundo esse autor, "poderíamos afirmar que só conhecemos de maneira significativa a porção do mundo que conseguimos criar" (SAFRA, 1999:44).

No aprofundamento do conceito winnicottiano de devoção, trabalhamos com o conceito de ágape (BOLTANSKI, 1990), cujas características identificamos na professora Sílvia. A acepção de ágape que concerne mais diretamente à pesquisa de Boltanski e que segundo ele interessa à Antropologia - e que adotamos em nosso constructo teórico - é o "amor às outras pessoas humanas, definido como o amor ao próximo". (BOLTANSKI,1990:171). Afirma o autor que o ágape entre os homens não se limita à comunidade eclesial, pois "ele tem por vocação manifestarse em presença de não importa qual pessoa, qualquer que seja a maneira pela qual ela poderia ser qualificada em outras relações. É nesse sentido que essa noção é disponível para a Antropologia". (BOLTANSKI,, 1990:171). Ressaltamos, portanto, que ao adotarmos tal conceito não estamos fazendo apologia às religiões. Ao abordarmos o ágape no Complexus (Morin, 1996) ${ }^{2}$ de nossa tecedura teórica, alinhamo-nos ao pensamento de Boltanski ao afirmar que "a operação de laicização do ágape advém de uma pura decisão de método, não se inscrevendo ela em uma teoria sociológica da religião." (BOLTANSKI,, 1990:154). Assim, ao associarmos o amor ágape ao conceito de amor devoção da mãe suficientemente boa, visamos a melhor caracterizar esse conceito de amor materno que estamos usando em nosso constructo teórico.

A professora Sílvia, portanto, foi reconhecida como esse próximo devotado, portadora do amor às outras pessoas humanas. Traduzindo esse amor em movimento na busca e adaptação ativa às necessidades do próximo, Sílvia demonstrou a capacidade de sair do próprio lugar - de sua estrutura interna de referência, do seu círculo estreito de relacionamentos - para colocar-se em presença dos moradores de rua. Essa presença ativa, empática, congruente (ROGERS, 1991) - aceitando-os tal qual se apresentavam, abrindo-lhes um lugar em si-mesma, fez com que se sentissem incondicionalmente aceitos. Livres, sem cobranças, eles confiaram naquela que se doava, abriram-se para o movimento de transformação no espaço da confiança que se formara entre ambos, na "sobreposição de duas áreas do brincar..." (WINNICOTT, 1975)

No Diagrama 1 está representado o encontro - explicitado acima - entre a professora portadora das características do ágape, na sua busca e adaptação ativa às necessidades do próximo, com os moradores de rua. 


\section{DLAGRAMA 1}

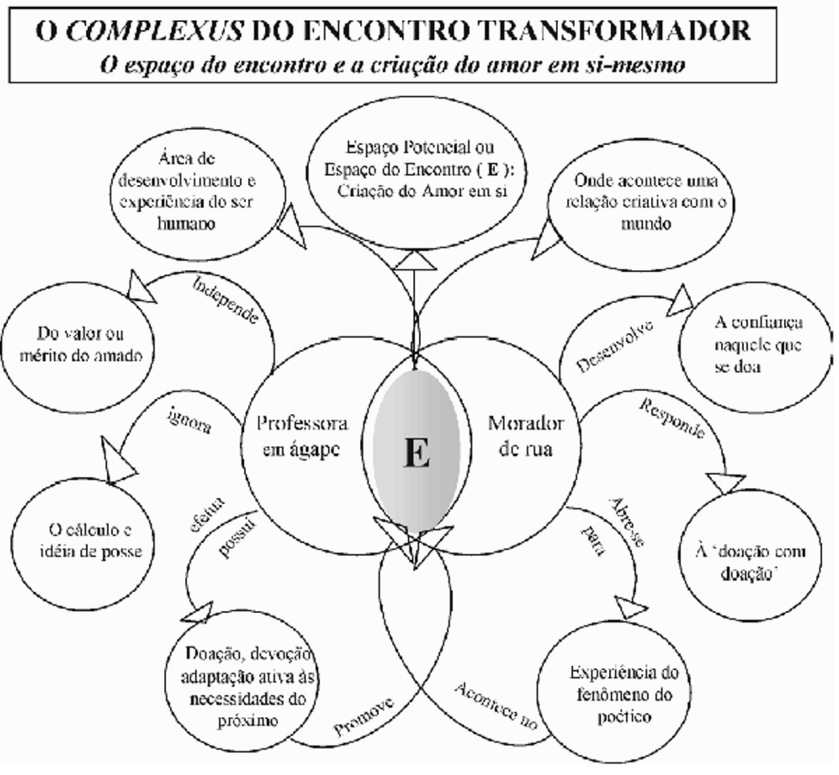

Sob o influxo dessa aceitação, em presença da professora, beberam a força que necessitavam para flexibilizar as amarras das psiques atormentadas, permitir que o caos organizador (MORIN, 1997:59) ${ }^{3}$ se instalasse em seus mundos interiores forjados no crime, no desespero. A forma do falso self de cada um dos moradores de rua - organização complexa e ativa mas também dispositivo de congelamento - iniciou um movimento de flexibilização, de desconstrução de suas defesas no processo regressivo que se instaurara junto à professora.

A respeito desse dispositivo de congelamento, Luiz Claudio Figueiredo afirma que o falso self "traz em si as marcas da "frozen situation", daí sua rigidez, apesar de sua evidente operatividade." Afirma ele que o indivíduo é mantido "ao mesmo tempo excessivamente acordado - impossibilitado, portanto, de dormir, de sonhar e brincar em serviço (no espaço potencial, no espaço da brincadeira; grifo nosso) - e com partes suas totalmente amortecidas, dormentes, congeladas, em estado de dissociação. Será preciso desconstruir as boas defesas do falso self oferecendo uma condição, já não mais sonhada nem desejada, de confiança no ambiente, e na possibilidade de retomar a situação de fracasso para descongelá-la e convertê-la em possibilidade de vida (grifos nossos)." 4

As psiques dos moradores de rua permitiram o rever-se: seus conteúdos congelados, soltando-se, foram reconhecidos por aqueles que - só então - puderam olhar-se no berço ágape ofertado pela professora devotada.

Desse caos, lentamente, foi-se anunciando nova gestalt, nova configuração psíquica, nova ordem, organização, transformação.

Na dança dos conteúdos esparsos das psiques do moradores de rua dançavam, também, os conteúdos do ágape que - a princípio RUÍDOS (FIEDLER-FERRARA, 1994; ATLAN, 1992) - num dado instante começaram a fazer sentido para aqueles que eram alvo da devoção: em presença da professora, eles criaram o amor em si. Ocorreu uma sobreposição entre o que a professora supria e o que os moradores de rua poderiam conceber. Estes perceberam os elementos do ágape apenas na medida em que o ágape poderia ser criado exatamente ali e naquele então (parafraseando WINNICOTT, 1975).

Nelson Fiedler-Ferrara explicita, a partir de Henri Atlan (1992), a complexidade a partir do ruído, "em que a capacidade de auto-organização de um sistema resulta de desorganizações seguidas de reorganizações em níveis de complexidade mais elevados. A criação de complexidade nutrese da desordem (ruído), onde o aleatório passa a ser parte integrante da organização." (FIEDLERFERRARA, 1987: 75-79)

Soviético - anteriormente personificado no mundo do abandono, da violência e do crime assim como Athos, ou Priscila - mergulhados no desespero e na violência das ruas - abriam-se à presença da professora-mãe, possibilitando o acontecimento de um novo corpo psico-emocional personificado através do processo que denominamos de maternagem tardia. Expressando a comunicação ativa com novos conteúdos internos criados em presença da professora devotada, expressaram em seus discursos o início de novas configurações emergentes em suas psiques, em movimentos que se encaminharam para transformação - nova for$m a$, nova organização - resistindo muitas vezes ao convite do crime.

Não foram, no entanto, somente os moradores de rua que se transformaram nos processos de encontros observados. Em cada busca ativa do próximo que empreendia, Sílvia cruzava o olhar consigo mesma, várias vezes caindo em si, refazendo caminhos onde não conseguira vivenciar a plenitude do ágape, as características desse amor em movimento. Deter o fluxo desse amor em si mesma, seria deter a própria vida, o acontecer de seu self no mundo. A partir do instante em que ela, Sílvia, criava nuanças desse amor em si - conhecendo-o de maneira significativa - deixar de vivê-lo a cada chamado equivaleria a deixar de ser, de existir. 
E dizemos que os moradores de rua transformaram-se porque novos sentimentos, significados em presença da professora, passaram a fazer parte de seus universos psíquicos: iniciou-se intenso processo de comunicação interna em cada um com as novas nuanças de sentimentos que descobriam em si. O crime - quando ainda realizado nesse processo de transformação em curso - já não acontecia livre e solto, sem nenhum outro estado diferenciado que se lhe antepusesse. É quando recolhemos expressões de lamento de Soviético por não ter conseguido manter-se na configuração do amor, é quando observamos movimentos incipientes da vontade de resistir ao crime. Acompanhamo-lo preso em sua batalha interna formidável, também através dos desenhos que realizou nesse período, onde pudemos observar o interjogo de forças configurando a transformação, o oscilar entre desilusão e esperança.

"Tem uns parceiro que chamam pra roubar e eu não vou roubar... tô sossegado, quero dar um tempo!..." (Soviético)

Nesse sentido, esses novos conteúdos internos de ágape foram por nós considerados como pontos de apoio que os alavancaram na resistência à criminalidade, no processo de estar no mundo, promovendo-lhes a resiliência.

A religiosidade - compreendida por Jung como função natural inerente à psique (JUNG, 1991:300) - também foi vivenciada pelos moradores de rua observados como relevante aspecto no processo de constituição do sentido da existência, como ponto fixo - ponto de apoio em suas psiques, alavancando seus projetos de estar no mundo, apontando um novo rumo para suas vidas atormentadas, favorecendo-lhes a resiliência.

Soviético, por exemplo, fez alusões à sua religiosidade em diversos momentos (observados ao longo dos cinco anos do processo da pesquisa), como o registrado em um desenho e nos comentários explicativos escritos ao lado do mesmo, produzidos durante uma aula ministrada pela professora Sílvia aos moradores de rua:

"Por que você desenhou a casa e a igreja?", perguntou-lhe Sílvia.

"Porque esta era a vida que eu queria ter. Minha casa onde eu pudesse ser feliz e com todos vivendo em harmonia... A igreja era o lugar onde ia me sentir bem e recebendo uma palavra amiga..."(Soviético, morador de rua)

Não seria a igreja de pedra ${ }^{5}$ à qual ele se referia: pelas ruas da grande cidade onde perambulava, podia encontrá-las muitas, enormes igrejas adornadas, de portas quase sempre abertas onde não entrava, conforme nos relatava em seus discursos espontâneos. Era outra sua igreja: associada à palavra amiga, lembrava a harmonia, o sentir-se aceito incondicionalmente, perto de Deus como estava ali, perto de sua professora.

E ela com devoção, no processo de maternagem (WINNICOTT, 1975), conduzia-o, a si e seus companheiros durante os exercícios de relaxamento ou durante as orações ao final das aulas, na vivência daquela função natural, inerente à psique, self desdobrando sua potencialidade no mundo. Banhava-os em amor - transfundindolhes a própria fé - que era criada e recriada por eles, que imprimiam a este sentimento um rítmo, uma realidade psíquica e um corpo próprios (SAFRA, 1999). Destacamos ainda, para a análise desse processo, as palavras de Gilberto Safra que afirma que a criatividade jamais é destruída, estando na origem do self a tendência do indivíduo para “... permanecer vivo e de se relacionar com objetos que aparecem no horizonte quando chega o momento de alcançá-los" (SAFRA, 1999:34).

Marcos, morador de rua observado, manifestava também em sua fala estreita associação entre sentimento de religiosidade e o acontecer do seu self no mundo, o desabrochar de suas potencialidades. Referiu-se também à solidariedade humana de Sílvia, apontando-a como a força que o auxiliou na retomada do sentido de sua vida. Priscila, acometida de tuberculose, a moradora da casa caverna - revela Deus em sua fala como a última instância à qual poderia recorrer, apelando a ele por providências que não acreditava mais que seriam tomadas pelo sistema político-social mais amplo que a ignorava:

"Porque de vez em quando me dá uma loucura na minha cabeça... (chorando) ... Eu não penso em fazer nada com ninguém, sabe?... Eu não tenho olho grande... eu não tenho inveja... eu só queria ter o que é $M E U$, entendeu? É o que eu sempre peço a Deus: que antes de eu morrer, que ele me desse pelo menos um barraquinho, sabe? Pra mim pôr uma cama, uma mesa, um fogãozinho dentro... aí eu falo: agora eu morro em paz, que Deus me deu tudo que eu queria, um lar..." (Priscila, moradora da casa caverna)

Não bastava o apoio dado pelas professoras devotadas - os próximos significativos Sílvia e Lucinha - sujeitos de observação do trabalho, ou mesmo o ponto de apoio representado pela presença do sentimento de Deus em suas vidas, para que a psique dos moradores de rua assumisse a estabilidade na resiliência, processo que se esboçava em cada um. Imersos no sistema social mais amplo que os ignorava, faltavam-lhes também os pontos de apoio do trabalho, do reconhecimento de seus 
Alvarez, A.M.S.; Alvarenga, A.T.; Ferrara, N.F. "O encontro transformador em moradores de rua na cidade de São Paulo"

direitos de cidadão, de poder ter um canto só seu uma casa, um lar - onde pudessem se manter, se fortalecendo inclusive nos propósitos de não reincidência na delinqüência.

\section{SOCIEDADE CIVIL E ESTADO E A PROMOÇÃO DA RESILIÊNCIA DO MORADOR DE RUA}

"Preocupamo-nos com a violência que mata, mutila e rouba. E não com a violência psíquica, social, afetiva que nos rodeia e anula o presente, roubando qualquer esperança de futuro para milhões de criaturas" (DAMERGIAN, 2001:103).

Afirmando ser a cidadania uma lei social que atinge a todos indistintamente e, ainda, que faz parte da mesma um conjunto de "princípios gerais e abstratos que se impõe como um corpo de direitos concretos individualizados" (SANTOS, 1998:7), Milton Santos, em outro momento de seu texto, argumenta que "o simples nascer investe o indivíduo de uma soma inalienável de direitos, apenas pelo fato de ingressar na sociedade humana. Viver, tornar-se um ser no mundo, é assumir, com os demais, uma herança moral, que faz de cada qual um portador de prerrogativas sociais. Direito a um teto, à comida, à educação, à saúde, à proteção contra o frio, à chuva, às intempéries; direito ao trabalho, à justiça, à liberdade e a uma existência digna" (SANTOS, 1998:7).

Refletindo a respeito dessas afirmações sobre cidadania e os sujeitos de observação - moradores de rua - focalizados neste trabalho, os identificamos como não pertencentes aos quadros de cidadania da sociedade brasileira. Não lhes bastou o simples nascer no seio dessa sociedade para que fossem investidos, de fato, de uma soma inalienável de direitos. Morando na rua, sem o suporte social, falta-lhes o essencial para uma existência digna. Claramente podemos perceber que, se existem cidadãos brasileiros investidos das prerrogativas sociais apontadas por Milton Santos, outros brasileiros há - e aqui não nos aventuramos em denominá-los como cidadãos - que estão à margem dessa herança a que teriam direito. Com exceção de um dos moradores de rua observados neste trabalho, todos os outros - Soviético, Athos, Marcos, Priscila e seu companheiro Paraíba - estiveram em algum momento de sua vida nas ruas envolvidos com a criminalidade. Eles constituem a face mais cruel e muitas vezes negada de uma sociedade desigual.

No Diagrama 2 representamos os percursos entre os processos reconhecidos como coleti- vos e outros singulares, visando a observar o conjunto da tecedura, o delineamento da organização complexa que se foi configurando ao longo desse trabalho.

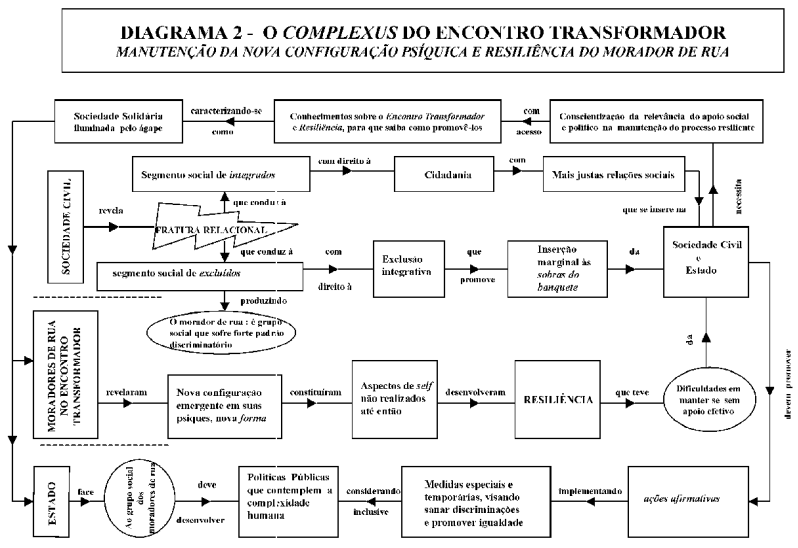

As qualidades emergentes das relações de encontro com segmentos da sociedade que atuaram no sentido de amparar os moradores de rua, serem seus pontos de apoio positivos, constatadas neste trabalho, traduzem por si mesmas o mérito e necessidade desse tipo de ação. No entanto, observou-se que os moradores de rua que retomaram o acontecer do self, reassumindo o processo criativo, no processo do encontro transformador com as professoras, tiveram dificuldades em manter a constância das novas formas configuradas, manter a transformação sem o apoio efetivo da Sociedade Civil e do Estado. Faltavam-lhes os pontos de apoio do trabalho, do reconhecimento dos seus direitos de cidadãos, de poderem ter uma casa, um lar, de viverem com dignidade, a qual implicava, também, que fossem reconhecidos como seres humanos pelos outros cidadãos brasileiros e pelo Estado, na sua responsabilidade na promoção de Políticas Públicas, norteadas por uma visão solidária de promoção do homem e justiça social.

\section{NOTAS}

1 Comunicação proferida por Luiz Cláudio Figueiredo no curso de Pós Graduação em Psicologia da Pontifícia Universidade Católica, em 2001, São Paulo [mimeo].

${ }^{2}$ Para Edgar Morin, "Complexus é o que está junto; é o tecido formado por diferentes fios que se transformaram numa só coisa, isto é, tudo isso se entrecruza, tudo se entrelaça para formar a unidade da complexidade; porém, a unidade do complexus não destrói a variedade das complexidades que o teceram." (Morin, 1996:188).

${ }^{3} \mathrm{O}$ "Caos organizador" é referido por Edgar Morin 
no sentido de um fenômeno de "duas faces", em que há ao mesmo tempo desintegração e organização, "criação/transformação". (Morin, 1997:59).

${ }^{4}$ Comunicação proferida por Luiz Cláudio Figueiredo no curso de Pós Graduação em Psicologia da Pontifícia Universidade Católica, em 2001, São Paulo [mimeo].

${ }^{5}$ Pretendemos deixar claro que não estamos fazendo, neste trabalho, a apologia a esta ou àquela religião e sim registrando e analisando essa função natural inerente à psique (Jung, 1991) que se configurou no decurso do processo da pesquisa.

\section{REFERÊNCIAS}

ALVAREZ, A. M. S. A resiliência e o morar na rua: estudo com moradores de rua - criança e adultos - na cidade de São Paulo. São Paulo, 1999. Dissertação (Mestrado em Saúde Pública) - Faculdade de Saúde Pública, Universidade de São Paulo.

ALVAREZ, A. M. S. La résilience et l'habitation dans la rue: étude des habitants de rue - enfants et adultes - dans la ville de São Paulo. In: DOUVILLE, O.; SABATIER, C. (Ed.). Cultures, insertions et sante. Paris: L'Harmattan, 2002. p. 277.

ALVAREZ, A. M. S. Resiliência e encontro transformador em moradores de rua na cidade de São Paulo. São Paulo, 2003. Tese (Doutorado em Saúde Pública) - Faculdade de Saúde Pública, Universidade de São Paulo.

ATLAN, H. Entre o cristal e a fumaça: ensaio sobre a organização do ser vivo. Rio de Janeiro: Zahar, 1992.

BOLTANSKI, L. L'amour et la justice comme compétences: trois essais de sociologie de l'action. Paris: Éditions Métailié,1990.

CALDEIRA, T. P. R. Cidade de muros: crime, segregação e cidadania em São Paulo. São Paulo: Ed. 34/EDUSP, 2000.

CARRETEIRO, T. C. Effort de survie et habit précaire. In: DOUVILLE, O.; RIDEL, L. (Org.) Exclusions, précarités: témoignages cliniques. Paris: L'Harmattan, 1999. (Psychologie Clinique; nouvelle série $\mathrm{n}^{\circ}$ 7). p.121-130.

DAMERGIAN, S. O papel do inconsciente na interação humana: um estudo sobre o objeto da psicologia social. São Paulo, 1988. Tese (Doutorado em Saúde Pública) - Instituto de Psicologia,
Universidade de São Paulo.

DAMERGIAN, S. A construção da subjetividade na metrópole paulistana: desafio da contemporaneidade. In: TASSARA, E. T. O. (Org.) Panoramas interdisciplinares para uma psicologia ambiental do urbano. São Paulo: Educ/FAPESP, 2001. p.87-120.

ERIKSON, E. H. Infância e sociedade. Rio de Janeiro: Zahar, 1976.

FIEDLER-FERRARA, N. Literatura e Complexidade. In: CASTRO, G.; CARVALHO, E.A. e ALMEIDA, M.C.(Orgs.) Ensaios de Complexidade. Porto Alegre: Sulina, 1997. p. 75-89.

GROTBERG, E. H. Guía de promocion de la resiliencia en los niños para fortalecer el espíritu humano. La Haya: Fundacion Bernard van Leer, 1996. (Informes de Trabajo sobre el Desarrollo de la Primera Infancia, 18)

JUNG, C. G. A natureza da psique. Petrópolis: Vozes, 1991. v. 8/2.

MAGNANI, J. G. C. De perto e de dentro: notas para uma etnografia urbana. Revista Brasileira de Ciências Sociais, São Paulo, v. 17, n. 49, p. 11-29, 2002.

MORIN, E. Ciência com consciência. Rio de Janeiro: Bertrand do Brasil, 1996.

MORIN, E. $O$ método - 1: a natureza da natureza. Portugal: Publicações Europa-América, 1997.

ROGERS, C.R. Tornar-se pessoa. São Paulo: Martins Fontes, 1991.

SAFRA, G. Momentos mutativos em psicanálise: uma visão Winnicottiana. São Paulo: Casa do Psicólogo, 1995.

SAFRA, G. A face estética do self: teoria e clínica. São Paulo: Unimarco Editora, 1999.

SANTOS, M. O espaço do cidadão. 4. ed. São Paulo: Nobel, 1998.

VÉRAS, M. P. B. Exclusão social: um problema de 500 anos. In: SAWAIA, B. (Org.) As artimanhas da exclusão social: análise psicossocial e ética da desigualdade social. Petrópolis: Vozes, 2001. p. 27-50. 
Alvarez, A.M.S.; Alvarenga, A.T.; Ferrara, N.F. "O encontro transformador em moradores de rua na cidade de São Paulo"

VIEIRA, M. A. C; RAMOS BEZERRA, E. M.; MAFFEI

ROSA, C. M. População de rua: quem é, como vive, como é vista. 2. ed. São Paulo: HUCITEC, 1994.

WINNICOTT, D. W. O brincar \& a realidade. Rio de Janeiro: Imago, 1975.

WINNICOTT, D. W. Os bebês e suas mães. São Paulo: Martins Fontes; 1988.

Aparecida Magali de Souza Alvarez é PósDoutoranda da Universidade de São PauloFaculdade de Saúde Pública. O endereço eletrônico da autora é: apmagali@terra.com.br

Augusta Thereza de Alvarenga é Docente da Universidade de São Paulo-Faculdade de Saúde Pública, Departamento de Saúde Materno-Infantil.

O endereço eletrônico da autora é: atal@usp.br

Nelson Fiedler-Ferrara é Docente do Instituto de Física da Universidade de São Paulo. $O$ endereço eletrônico do autor é: ferrara@fge.if.usp.br

\author{
Aparecida Magali de Souza, Agusta Thereza \\ de Alvarenga e Nelson Fiedler Ferrara. \\ O "encontro transformador"em moradores \\ de rua na cidade de São Paulo \\ Recebido dia 24/09/2004 \\ $1^{\text {a }}$ revisão: 16/12/2004 \\ Aceite final: 21/01/2005
}

